\title{
Regulation of ovulatory genes in bovine granulosa cells: lessons from siRNA silencing of PTGS2
}

\author{
Ketan Shrestha, Karolina Lukasik ${ }^{1}$, Anja Baufeld ${ }^{2}$, Jens Vanselow ${ }^{2}$, Uzi Moallem ${ }^{3}$ and Rina Meidan \\ Department of Animal Sciences, The Robert H. Smith Faculty of Agriculture, Food and Environment, The Hebrew \\ University of Jerusalem, Rehovot 76100, Israel, ${ }^{1}$ Department of Reproductive Immunology and Pathology, Institute of \\ Animal Reproduction and Food Research, Polish Academy of Science, Olsztyn, Poland, ${ }^{2}$ Department of Reproductive \\ Biology, Leibniz Institute of Farm Animal Biology, Dummerstorf, Germany and ${ }^{3}$ Department of Ruminant Science, \\ Agricultural Research Organization, Bet-Dagan, Israel
}

Correspondence should be addressed to R Meidan; Email: rina.meidan@mail.huji.ac.il

\begin{abstract}
Prostaglandin endoperoxide synthase-2 (PTGS2), tumour necrosis factor-alpha-induced protein-6 (TNFAIP6), pentraxin-3 (PTX3), epidermal growth factor-like factors: amphiregulin (AREG) and epiregulin (EREG) are essential for successful ovulation. In this study, we compared the induction of these ovulatory genes in bovine granulosa cells (GCs) in vivo (after LH surge) and in vitro (forskolin (FRS) treatment). These genes were markedly stimulated in GCs isolated from cows $21 \mathrm{~h}$ after LH-surge. In isolated GCs, FRS induced a distinct temporal profile for each gene. Generally, there was a good agreement between the in vivo and in vitro inductions of these genes except for PTX3. Lack of PTX3 induction in isolated GCs culture suggests that other follicular compartments may mediate its induction by LH. Next, to study the role of PTGS2 and prostaglandins (PGs) in the cascade of ovulatory genes, PTGS2 was silenced with siRNA. PTGS2 siRNA caused a marked and specific knockdown of PTGS2 mRNA and PGE2 production (70\% compared with scrambled siRNA) in bovine GCs. Importantly, PTGS2 silencing also reduced AREG, EREG and TNFAIP6 mRNA levels but not PTX3. Exogenous PGE2 increased AREG, EREG and TNFAIP6 mRNA levels, further confirming that these genes are prostanoid dependent. A successful and specific knockdown of PTGS2 was also achieved in endometrial cells (EndoCs) expressing PTGS2. Then, cholesterol-conjugated PTGS2 (chol-PTGS2) siRNA that facilitates cells' entry was investigated. In EndoCs, but not in GCs, chol-PTGS2 siRNA succeeded to reduce PTGS2 and PGE2 levels even without transfection reagent. PTGS2 knockdown is a promising tool to critically examine the functions of PTGS2 in the reproductive tract.

Reproduction (2015) 149 21-29
\end{abstract}

\section{Introduction}

Ovulation is triggered by LH surge. The LH receptor activates several families of heterotrimeric G-proteins, but the activation of Gs and cAMP/PKA cascade is widely accepted as an important downstream signalling of LH action (Fan et al. 2011, Breen et al. 2013). It brings about series of changes such as resumption of meiosis in the oocyte, reprogramming of the granulosa cells (GCs) and theca cells (TCs) layer of the follicular wall. These events are accompanied by the expression of new mRNAs and proteins and result in the release of a fertilisable oocyte and the luteinisation of follicular cells (Richards 2001, 2005). In preparation for oocyte expulsion, the extracellular matrix (ECM) of cumulusoocyte complex (COC) undergoes remodeling (Richards 1994, Salustri et al. 1996). A number of genes mediating these processes have been identified, amongst them are prostaglandin endoperoxide synthase 2 (PTGS2), tumour necrosis factor-alpha-induced protein 6 (TNFAIP6), pentraxin 3 (PTX3), epidermal growth factor (EGF)-like factors: amphiregulin (AREG) and epiregulin (EREG) (Mukhopadhyay et al. 2001, Salustri et al. 2004, Conti et al. 2006, Bridges \& Fortune 2007).

LH-induced PTGS2 in the GCs layer increases prostaglandins (PGs), especially PG endoperoxide 2 (PGE2) in the follicular fluid (Sirois \& Richards 1992, Sirois 1994, Tsai et al. 1996, Liu et al. 1997). The essential role of PTGS2 is demonstrated in gene-knockout experiments and PTGS inhibitors studies which resulted in failed ovulation with normal luteinisation and corpus luteum formation (Dinchuk et al. 1995, Davis et al. 1999, Peters et al. 2004). Later, it was demonstrated that LH/ hCG upregulate EGF-like factors in murine GCs; these peptides mediated $\mathrm{LH}$ action in COC expansion and oocyte maturation (Park et al. 2004, Conti et al. 2006, Shimada et al. 2006). During COC expansion, LH surge also induces TNFAIP6, which is a hyaluronan (HA)binding protein (Lee et al. 1992) critical for the stability of glycosaminoglycan HA-rich ECM (Ochsner et al. 2003). A study of Tnfaip6-knockout mice showed defective COC expansion and infertility (Fulop et al. 2003). 
Likewise, PTX3, belonging to the long pentraxin family of inflammatory proteins, was expressed in COC (Varani et al. 2002, Salustri et al. 2004). It plays a protective role during the formation of HA-rich matrix of the COC by cross-linking HA polymers through interactions with heavy chains of inter- $\alpha$ trypsin inhibitor (Ial) and/or TNFAIP6 (levoli et al. 2011). An abnormal COC expansion characterised by unstable extracellular matrix was reported in Ptx3-deficient mice (Salustri et al. 2004). Thus, PTGS2, EGF-like factors (AREG and EREG) and HA-binding proteins (TNFAIP6 and PTX3) are all the obligatory factors for ECM stability, COC expansion and follicular rupture.

Most of our knowledge on ovulatory genes stems from rodents, especially mice; however reproductive strategies differ in rodents and large mono-ovulatory animals. Therefore, data from rodents cannot always be extrapolated in mono-ovulatory mammals such as bovine (Bahr \& Wolf 2012). In addition, these animals are not amendable for gene deletion studies. In such species, siRNA can be used as a means for gene knockdown (Fang et al. 2013). Therefore, we aimed herein to study the induction of ovulatory genes in bovine GCs under in vivo and in vitro conditions. siRNA silencing of PTGS2 was used to critically examine the role of PGE2 in the cascade of events in GCs that leads to ovulation. As a proof of concept we also employed endometrial cells (EndoCs), these cells, similar to GCs, express PTGS2 and their synthesised PGs play significant physiological roles.

\section{Materials and methods \\ Animals and sample collection}

Follicles were collected from Holstein-Friesian cows as described (Vanselow et al. 2010, Christenson et al. 2013). Large dominant follicles before LH surge were collected after carefully, monitoring a growing cohort of follicles in normally cycling cows by transrectal ultrasonography (Aloka SSD-500, Aloka $\mathrm{GmbH}$, Meerbusch, Germany). The animals were slaughtered at days $7(n=1)$ and $8(n=2)$ of the estrous cycle during the first follicular wave. Only the largest growing, but not stagnating or regressing, follicle of each animal was collected. To collect dominant follicles after the LH surge, normally cycling cows were treated with $500 \mu$ P PGF2a (PGF Veyx forte, Veyx Pharma GmbH, Schwarzenborn, Germany) at day 8 of the cycle, to induce luteolysis. Forty-eight hours later, the animals were injected with $100 \mu \mathrm{g}$ of a gonadotrophin-releasing hormone (GNRH) analogue (GonavetVeyx, Depherelin, Veyx Pharma $\mathrm{GmbH}$ ) to induce the $\mathrm{LH}$ surge. The animals were slaughtered $23 \mathrm{~h}$ later and the largest growing follicle of each animal was isolated $(n=3)$. The GCs were collected by aspiration of the follicular fluid with an 18G needle. The fluid was centrifuged $(2 \mathrm{~min}, 400 \mathrm{~g}$ ) and the sediment cells were frozen in liquid nitrogen and stored at $-80{ }^{\circ} \mathrm{C}$ for RNA preparation. RNA isolation, $\mathrm{RT}$ and $\mathrm{qPCR}$ were carried out as described previously (Christenson et al. 2013).
All procedures involving living animals (injections and ultrasonography examinations in cattle) were performed according to the German law for animal protection (8a TierSchG i.V.m. 29 Tierschutz-Versuchstierverordnung). The named procedures are not subjected to specific permit by the governmental authority Landesamt für Landwirtschaft, Lebensmittelsicherheit und Fischerei (LALLF) Rostock.

\section{Isolation and culture of GCs}

The ovaries were collected at a local abattoir as described previously (Meidan et al. 1990). The GCs were enzymatically dispersed by using a combination of collagenase I ( 125 units/ml), hyaluronidase III (36 units/ml) and deoxyribonuclease I (11 units/ml) in DMEM/F-12 containing $2 \mathrm{mM}$ L-glutamine and $100 \mu \mathrm{g} / \mathrm{ml}$ of penicillin/streptomycin. Only large follicles ( $>10 \mathrm{~mm}$ in diameter) containing $\geq 4$ million viable cells were used. The GCs were cultured overnight in a medium containing $3 \%$ FCS. The cells were then incubated with DMEM/F-12 containing 1\% FCS (control) and with PGE2 $(1 \mu \mathrm{M}$; Cayman Chemical Co., Ann Arbor, MI, USA) or with forskolin (FRS; $10 \mu \mathrm{M}$ ) for various time points as indicated. Unless otherwise stated all biochemicals were from Sigma-Aldrich and cell culture materials were from Biological Industries, Kibbutz Beit Haemek, Israel.

\section{Isolation and culture of EndoCs}

Uterine horns from cows at late luteal phase were collected from the abattoir (Arosh et al. 2002). Endometrial strips were dissected and incubated in an enzyme solution (18 units $/ \mathrm{ml}$ DNAse and 315 units $/ \mathrm{ml}$ collagenase I) at $38{ }^{\circ} \mathrm{C}$ for $25 \mathrm{~min}$ in a shaking water bath. The cell suspension was filtered with a cell strainer, centrifuged and cultured in DMEM/F-12 containing $10 \%$ FCS. Confluent plates were trypsinised with trypsin EDTA solution $(0.25 \%$ trypsin and $0.02 \%$ EDTA). The cells of passages 2-3 were utilised in this study. Based on morphology and growth in culture, the cells were identified as endometrial stromal cells (Cherny \& Findlay 1990).

\section{Transfection of cells}

For transfection experiments, GCs were trypsinised with trypsin EDTA solution $(0.05 \%$ trypsin and $0.02 \%$ EDTA) immediately after isolation from follicles. The trypsinised cells were seeded $\left(3 \times 10^{5}\right.$ GCs; $0.8 \times 10^{5}$ EndoCs $)$ in six-well plates and cultured for up to $24 \mathrm{~h}$ in $3 \%$ FCS. Then cells were transfected using Lipofectamine 2000 reagent (Invitrogen) in 1\% FCS, according to the manufacturer's protocol. The cells were transfected with siRNA sequence, targeting $(50 \mathrm{nmol} / \mathrm{l})$ naked PTGS2 siRNA or cholesterol-conjugated PTGS2 (chol-PTGS2) siRNA or scrambled siRNA. The sequence of naked PTGS2 siRNA was sense (S), GUGAAAGGCUGUCCCUUUA[dT][dT], antisense (AS), UAAAGGGACAGCCUUUCAC[dT][dT] corresponding to bases 1781-1799 of the bovine PTGS2 mRNA sequence (NM_174445). The sequence for chol-PTGS2 siRNA was same as for naked PTGS2 siRNA with cholesterol conjugation in $3^{\prime}$ end of sense strand: S, GUGAAAGGCUGUCCCUUUA $[\mathrm{dA}][\mathrm{dT}][$ CholTEG], AS, UAAAGGGACAGCCUUUCAC $[d A][d T]$. Scrambled siRNA sequence-negative control was $S$, 
UUCUCCGAACGUGUCACGU[dT][dT], and AS, ACGUGACACGUUCGGAGAA[dT][dT]. A day after transfection, PTGS2 was induced in GCs by FRS $(10 \mu \mathrm{M})$ and in EndoCs by phorbol 12-myristate 13-acetate (PMA; $100 \mathrm{ng} / \mathrm{ml}$ ), then the cells were harvested and total RNA was extracted from cells $48 \mathrm{~h}$ after transfection.

For treatment of GCs and EndoCs in the absence of transfection reagent, the cells were incubated with cholPTGS2 siRNA for $24 \mathrm{~h}$ and total RNA was extracted from cells after $48 \mathrm{~h}$.

\section{RNA extraction and real-time PCR}

Total RNA was isolated from the cells using TriFast reagent (Peqlab Biotechnologie GmbH, Erlangen, Germany) according to the manufacturer's instructions: $1 \mu \mathrm{g}$ of total RNA was reverse transcribed using M-MuLV Reverse Transcriptase (200 units/ $\mu \mathrm{l}$ ), M-MuLV RT Buffer (New England Biolabs, Ipswich, MA, USA), random primer (100 nM), oligo-dT $(100 \mu \mathrm{M})$ and dNTPs mix (100 mM) (Bioline Reagents Limited, London, UK). Real-time PCRs were carried out using the Mx3000P system (Stratagene, Garden Grove, CA, USA), using Platinum SYBR Green (SuperMix, Invitrogen), as previously described (Klipper et al. 2009). Gene expression (PTGS2, TNFAIP6, PTX3, AREG and EREG) was analysed by quantitative real-time PCR. The glyceraldehyde-3-phosphate dehydrogenase $(G A P D H)$ gene was used as the housekeeping gene. The threshold cycle number $(C \mathrm{t})$ was used to quantify the relative abundance of the gene; arbitrary units were calculated as $2^{-\Delta C t}=2^{-(C t \text { target gene }-C t \text { housekeeping gene) }}$. The primer sequences used were as follows: GAPDH (NM_001034034) forward: 5'-GTCTTCACTACCATGGAGAAGG-3', reverse: 5'-TCATGGATGACCTTGGCCAG-3'; PTGS2 (NM_174445) forward: 5'-CAGCGGTGCAGCAAATCCTTG-3', reverse: 5'-CTGTGTTGGGAGTGGGTTTCA-3'; AREG (NM_001099092) forward: 5'-CTATAGCTGCTTTCGTCTCTGC-3', reverse: 5'-CGTTCTTCAGCGACACCTTCA-3'; EREG (XM_002688367) forward: 5'-CTGCTGCTCGTCCTGGTTTTC-3', reverse: 5'-GCTGTGCAGTTATCTCCCGAC-3'; TNFAIP6 (NM_00100 7813) forward: 5'-ATGGCTTGAACAAGCAGCAGG-3', reverse: 5'-GCCATCCACCCAGCAGCACA-3'; PTX3 (NM_001076259) forward: 5'-AGCСТCTTGCСТCGTCСССТC-3', reverse: 5'-TCTGAGTTCTCCGCCGACACT-3'; VEGF (NM_174216) forward: 5'-CCATGAACTTTCTGCTCTCTTGG-3', reverse: 5'-TCCATGAACTCCACCACTTCG-3'; SLC2A1 (NM_174602) forward: 5'-CGCTTCСTGCTCATTAACCG-3', reverse: 5'-CСТTCTTCTCCCGCATCAT-3'; TNFR1 (NM_174674) forward: 5'-GGCGAGACACGGACTGCA-3', reverse: 5'-TCCCGGTCCACTACACAAGG-3'.

\section{PGE2 analysis}

Media from the cell cultures were collected on the day of RNA isolation. The levels of PGE2 were measured by PGE2 enzyme Immunoassay Kit - monoclonal (Cayman Chemical Co.) according to manufacturer's instruction. The standard curve ranged from 6.4 to $1000 \mathrm{pg} / \mathrm{ml}$. Cross reactivity of the assay with PGE2 was 100 and $0.01 \%$ for PGF2a.

\section{Statistical analyses}

Data are presented as means \pm s.E.M.; experiments were repeated at least three times. The expression of specific mRNA transcripts was normalised relative to the abundance of GAPDH mRNA. Data were analysed by Student's $t$-test. Differences were considered significant at $P<0.05$. Asterisks represent significant differences from their respective controls. ${ }^{*} P<0.05$, ${ }^{* *} P<0.01,{ }^{* * *} P<0.001$, **** $P<0.0001$.

\section{Results}

\section{In vitro and in vivo induction of ovulatory genes}

hCG (Fig. 1A inset) and LH (data not shown) induced PTGS2; however, LH/hCG response was variable therefore FRS was used instead as an activator of adenylyl cyclase. The primary bovine GCs were cultured in the absence or presence of FRS $(10 \mu \mathrm{M})$ for $6-24 \mathrm{~h}$. There was a distinct temporal profile of induction for each gene (Fig. 1). A significant induction of PTGS2 (Fig. 1A) was

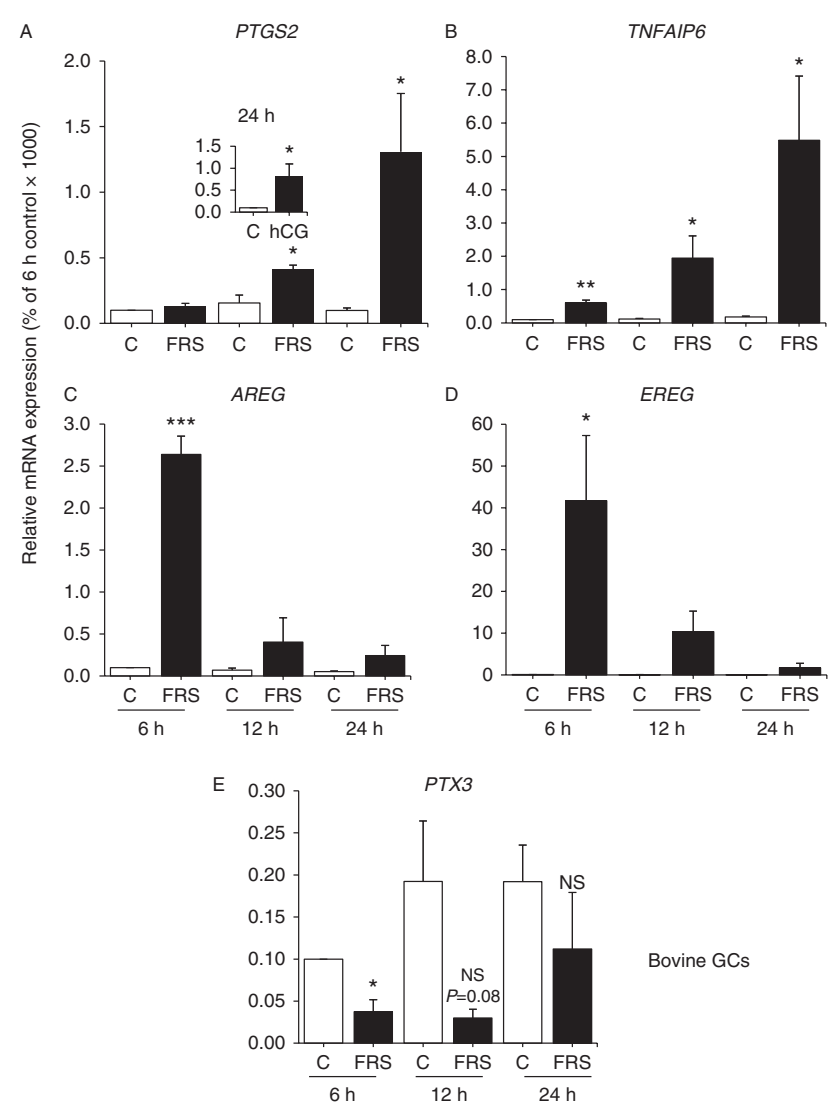

Figure 1 In vitro expression of (A) PTGS2, (B)TNFAIP6, (C) AREG, (D) EREG and (E) PTX3 in bovine GCs. GCs were incubated with or without (control: C) forskolin (FRS; $10 \mu \mathrm{M}$ ) for 6,12 and $24 \mathrm{~h}$, when cells were collected for RNA extraction. mRNA expression was measured by quantitative real-time PCR. Control levels at $6 \mathrm{~h}$ were designated $100 \%$. The results are mean \pm s.E.M. from three independent experiments. ${ }^{*} P<0.05,{ }^{* *} P<0.01$ and ${ }^{* * *} P<0.001$ indicate significant differences from their respective controls. Inset: GCs were incubated with hCG (10 IU) for $24 \mathrm{~h}$. 
observed at $12 \mathrm{~h}$ (threefold), which was further elevated (13-fold compared with its control) at $24 \mathrm{~h}$. Induction of TNFAIP6 followed a similar pattern to that of PTGS2, but a maximal fold stimulation was much higher (30-fold; Fig. 1B). Unlike to these two genes, AREG and EREG were maximally induced already at $6 \mathrm{~h}$ and then FRS effect decreased gradually until $24 \mathrm{~h}$ (Fig. 1C and D). Amongst the genes studied, EREG was highly expressed. In contrast to other genes, PTX3 was decreased in the presence of FRS at all time point examined (Fig. 1E).

In vivo as well, comparing the mRNA expression in GCs collected before and $21 \mathrm{~h}$ after $\mathrm{LH}$ administration to cows reveals a marked stimulation of these genes by LH. PTGS2, TNFAIP6 and PTX3 were strongly upregulated (Fig. 2A, B and E). AREG and EREG on the other hand were only moderately induced at this time point (Fig. 2C and D).

\section{Effect of PGE2 on ovulatory genes}

To examine the role of endogenous PGs we employed siRNA targeting PTGS2. The mRNA levels of PTGS2 were significantly inhibited. PTGS2 levels were only $30 \%$ of those present in GCs treated with scrambled siRNA (Fig. 3A). In accordance, the concentration of PGE2 in the cell culture media was also strongly reduced to $<1 / 3$ as compared with scrambled siRNA (Fig. 3B). Silencing was specific to PTGS2 because non-related genes such as vascular endothelial growth factor (VEGF) and solute carrier family 2 (facilitated glucose transporter), member 1 (SLC2A1) were not affected (Fig. 3C). PTGS2 knockdown affected some of the ovulatory genes studied. Along with $70 \%$ inhibition of PTGS2, the mRNA
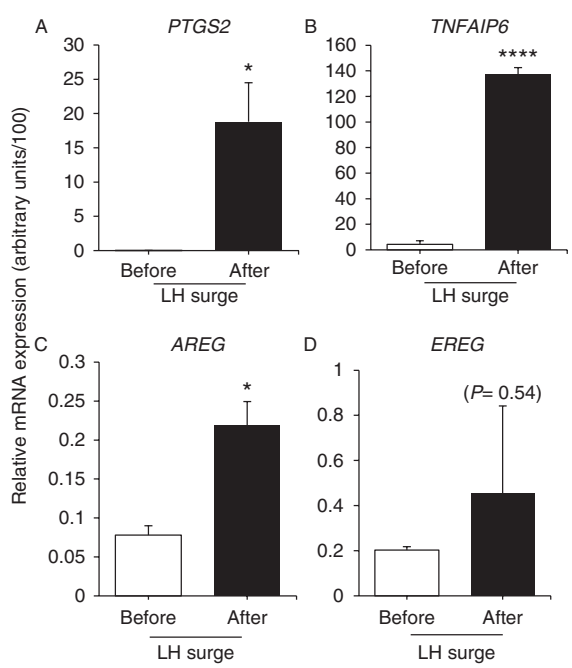

Bovine GCs

Figure 2 In vivo expression of (A) PTGS2, (B) TNFAIP6, (C) AREG, (D) EREG and (E) PTX3 in bovine GCs. GCs were aspirated from cows before $(n=3)$ and $21 \mathrm{~h}$ after GNRH-induced LH surge $(n=3)$. mRNA expression was measured by quantitative real-time PCR. The results are mean \pm S.E.M. $* P<0.05, * * P<0.01$ and $* * * * P<0.0001$ indicate significant differences from the follicles collected before $\mathrm{LH}$ surge.
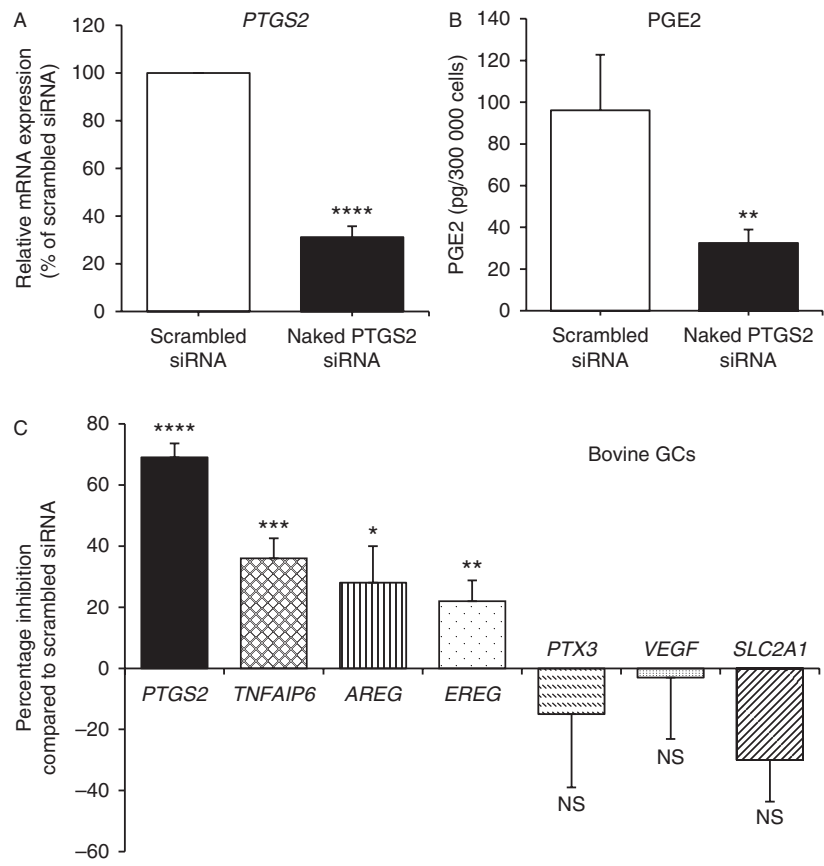

Figure 3 Effects of PTGS2 gene silencing on PGE2 concentration and ovulatory gene expression in bovine GCs. Bovine GCs were transfected with $50 \mathrm{nmol} / \mathrm{l}$ of scrambled siRNA; designated $100 \%$ or siRNA targeting PTGS2 (naked PTGS2 siRNA). 24 h post-transfection forskolin $(10 \mu \mathrm{M})$ was added. RNA was extracted $48 \mathrm{~h}$ post transfection and mRNA levels were measured using quantitative real-time PCR. Scrambled siRNA was designated as $100 \%$. (A) PTGS2 expression (B) PGE2 concentrations in culture media of cells transfected with scrambled siRNA or naked PTGS2 siRNA. (C) Percent inhibition of PTGS2, TNFAIP6, AREG, EREG, PTX3, VEGF and SLC2A1 compared with scrambled siRNA ( $0 \%)$. The data were obtained from five independent experiments. ${ }^{*} P<0.05,{ }^{*} P<0.01,{ }^{* * *} P<0.001$ and $* * * * P<0.0001$ indicate significant differences from scrambled siRNA.

levels of TNFAIP6, AREG and EREG were significantly inhibited by 40,30 and $20 \%$ respectively (as compared with $0 \%$ inhibition by scrambled siRNA; Fig. 3C). Notably, however, PTX3 was not affected by PTGS2 silencing (Fig. 3C).

To further strengthen these findings, we examined next the effect of exogenous PGE2 on AREG, EREG, TNFAIP6 and $P T X 3$. Bovine GCs were cultured in presence and absence of PGE2 $(1 \mu \mathrm{M})$ for 3-24 h. The effect of PGE2 subsided with time. At $6 \mathrm{~h}$, as given in Table 1, maximal effect of PGE2 was observed and expression of AREG, EREG and TNFAIP6 was significantly upregulated. As with PTGS2 silencing, the expression of PTX3 was not affected by PGE2. PGE2 did not modulate PTGS2 expression (data not shown).

\section{PTGS2 silencing with naked siRNA and cholesterol-conjugated siRNA in GCs and EndoCs}

We then compared naked siRNA with cholesterolconjugated siRNA molecule that does not necessitate transfection reagent. First, in bovine GCs, we examined 
Table 1 Induction of ovulatory genes in bovine granulosa cells by $6 \mathrm{~h}$ treatment with PGE2 $(1 \mu \mathrm{M})$.

\begin{tabular}{lcl}
\hline Gene & Fold over control & P value \\
\hline AREG & $3.4 \pm 1.08$ & 0.0016 \\
EREG & $11.8 \pm 3.42$ & 0.019 \\
TNFAIP6 & $2.2 \pm 0.49$ & 0.04 \\
PTX3 & $1.0 \pm 0.12$ & NS \\
\hline
\end{tabular}

Expression of each gene is as compared with its control designated as 1 . $n=4$.

the efficiency of chol-PTGS2 siRNA using a transfection reagent. Similar to the naked siRNA molecule, the mRNA levels of PTGS2 were declined to $65 \%$ as compared with scrambled siRNA (Fig. 4A). As expected PGE2 level were also reduced (data not shown). Likewise, TNFAIP6 expression was inhibited by $43 \%$ (Fig. 4B). However, when bovine GCs were treated with chol-PTGS2 siRNA without transfection reagent, no inhibition of PTGS2 or TNFAIP6 was observed.

Since bovine EndoCs also express the PTGS2, we next examined the effects of these siRNA molecules in bovine EndoCs. To induce PTGS2 in these cells, PMA $(100 \mathrm{ng} / \mathrm{ml})$ (Parent \& Fortier 2005) was utilised (Fig. 5A). When transfected with naked siPTGS2, a significant reduction was observed in the mRNA levels and PGE2 concentration by 65 and $91 \%$ respectively (Fig. 5B and C). Tumour necrosis factor receptor (TNFR1), another gene expressed in same levels as that of PTGS2 in bovine EndoCs, was unaffected by the siRNA (Fig. 5D), indicating specificity of the silencing process. In a similar manner to naked siPTGS2, transfection of chol-PTGS2 siRNA in EndoCs showed $68 \%$ reduction in PTGS2 mRNA levels (Fig. 6A). But in this cell type, chol-PTGS2 siRNA treatment without transfection reagent significantly reduced PTGS2 mRNA levels and PGE2 concentration (25 and 50\% respectively) (Fig. 6B and C).

\section{Discussion}

The present data demonstrated that ovulatory genes, namely PTGS2, TNFAIP6, AREG, EREG and PTX3 were upregulated in bovine GCs $21 \mathrm{~h}$ after an induced $\mathrm{LH}$ surge. Except PTX3, the other genes studied were also induced by FRS treatment in isolated GCs culture in vitro. AREG and EREG were induced abruptly (at $6 \mathrm{~h}$ ) during culture and progressively declined until $24 \mathrm{~h}$. PTGS2 and TNFAIP6 showed a different pattern with gradual induction of FRS, reaching a maximum at $24 \mathrm{~h}$. Using siRNA, we achieved a marked and specific silencing of PTGS2 in bovine GCs and another cell type expressing PTGS2, EndoCs. Reduction in PTGS2 mRNA levels in turn results in declined PGE2 concentrations in the culture media of both cell types. PTGS2 knockdown in GCs also inhibited the expression of ovulatory genes TNFAIP6, AREG and EREG, but not PTX3. In agreement, PGE2 treatment of GCs elevated the expression of these genes, except PTX3. Together these studies suggest that PGs, most likely PGE2, which are induced in GCs by LH/cAMP promote the expression of TNFAIP6, AREG and EREG (Fig. 7).

Interesting observations emerged from the comparison of in vivo and in vitro data. Although AREG and EREG were induced by $\mathrm{LH}$ surge, their fold inductions were low, in comparison with PTGS2 and TNFAIP6. The in vitro temporal pattern suggests that this may be due to the fact that AREG and EREG expression had already resided at $24 \mathrm{~h}$ after being highly induced at earlier time points. Another important observation is related with PTX3, which is considered as a bona fide ovulatory protein necessary for ECM stability during cumulus expansion (Varani et al. 2002, Salustri et al. 2004). PTX3, as shown before and also in this study, is induced in GCs by the LH surge in mice and bovine (Varani et al. 2002, Christenson et al. 2013). However, our study demonstrates that although GCs do express PTX3, it was not induced in isolated cell culture but rather inhibited by elevated cAMP levels. In fact, the mode of PTX3 induction is not well established yet and warrants

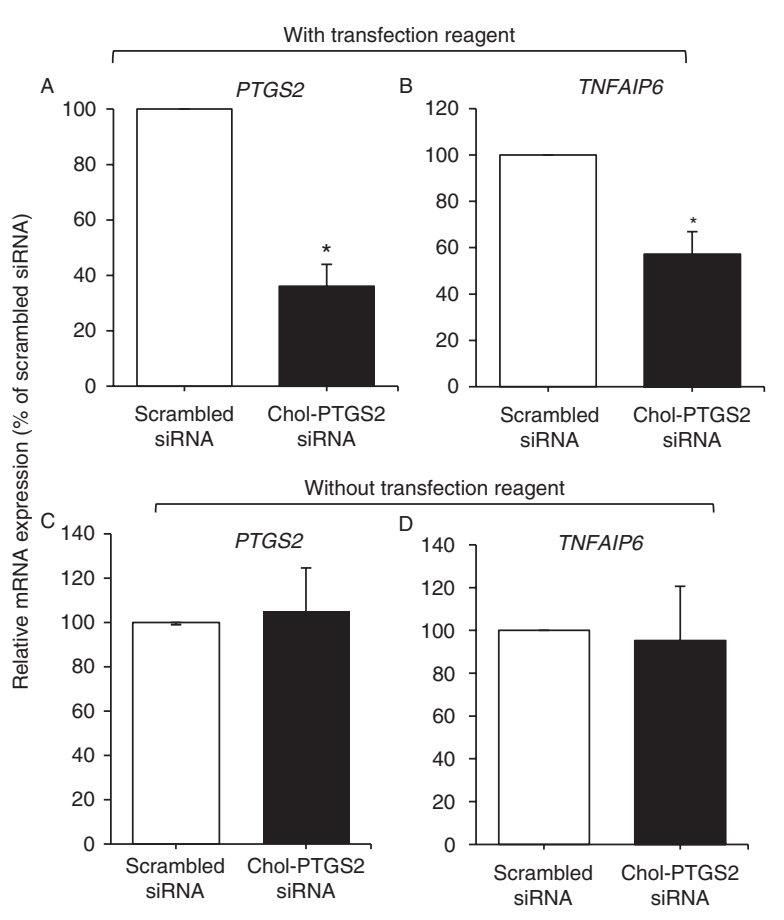

Figure 4 Cholesterol-conjugated PTGS2 siRNA treatment in bovine GCs with and without transfection reagent. Bovine GCs were treated with $50 \mathrm{nmol} / \mathrm{l}$ of scrambled siRNA (negative control; designated $100 \%$ ) or cholesterol-conjugated PTGS2 siRNA (chol-PTGS2 siRNA) with transfection reagent ( $A$ and $B$ ) or without transfection reagent (C and D). $24 \mathrm{~h}$ post transfection/treatment forskolin $(10 \mu \mathrm{M})$ was added and RNA was extracted $48 \mathrm{~h}$ post transfection/treatment the cells. mRNA levels were measured using quantitative real-time PCR. Scrambled siRNA was designated as $100 \%$. The data were obtained from three independent experiments. ${ }^{*} P<0.05$ indicates significant difference from scrambled siRNA. 

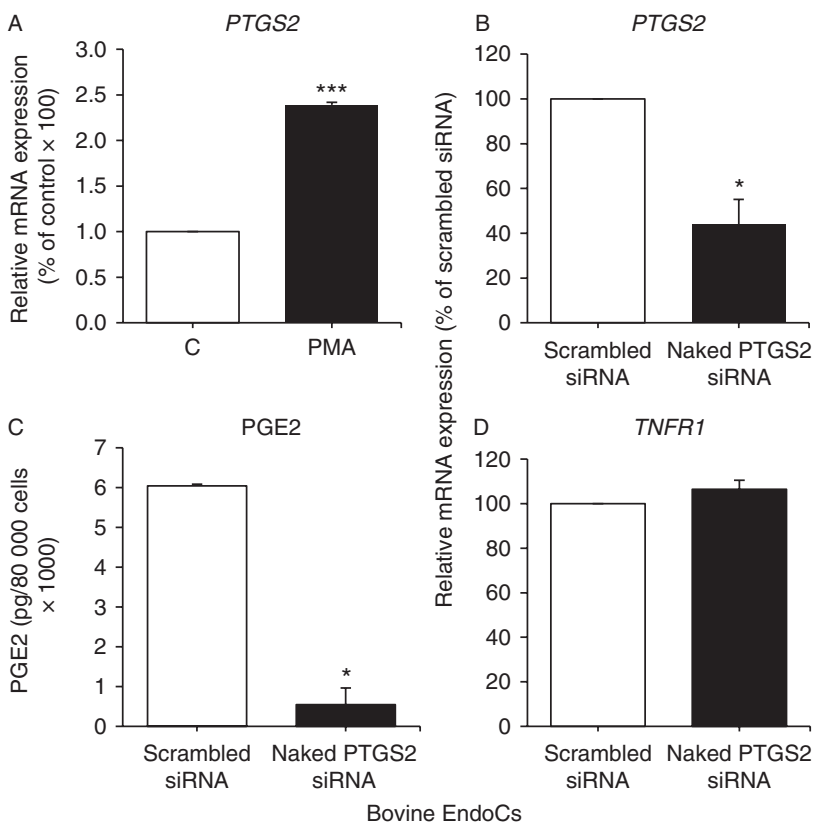

Figure 5 Expression of PTGS2 and PGE2 concentrations in bovine endometrial cells. (A) PTGS2 expression in bovine EndoCs incubated with or without PMA $(100 \mathrm{ng} / \mathrm{ml})$ for $24 \mathrm{~h}$. (B) Silencing of PTGS2 in bovine EndoCs. The cells were transfected with $50 \mathrm{nmol} / \mathrm{l}$ of scrambled siRNA; designated $100 \%$ or siRNA-targeting PTGS2 (naked PTGS2 siRNA). $24 \mathrm{~h}$ post transfection PMA (100 g/ml) was added and RNA was extracted $48 \mathrm{~h}$ post transfection. mRNA levels were measured using quantitative real-time PCR. (C) PGE2 concentrations in culture media of cells transfected with scrambled siRNA or naked PTGS2 siRNA. (D) TNFR1 expression in scrambled siRNA and naked PTGS2 siRNA transfected cells. The data were obtained from four independent experiments. ${ }^{*} P<0.05$ and ${ }^{* * *} P<0.001$ indicate significant differences from scrambled siRNA.

further investigation. Yet, lack of induction in isolated GCs culture strongly suggests that other follicular compartments may mediate its induction by $\mathrm{LH}$. Indeed in vitro induction of PTX3 (by CAMP and PGE2) was demonstrated in the past only in murine COC, where the presence of oocyte appears to be essential (Salustri et al. 2004).

The temporal and functional relationship between PGs and EGF-like factors has been inconclusive. Ptgs2knockout mice have reduced level of Areg and Ereg (Shimada et al. 2006). In agreement, PGE2 induces $A R E G$ and EREG in a dose-dependent fashion in human GCs (Ben-Ami et al. 2006). Moreover, injecting intrafollicular indomethacin (INDO) in cows showed reduced AREG expression in GCs (Li et al. 2009). These reports tend to suggest that PTGS2 induces EGF-like factors. Other studies favour the concept of PTGS2 being induced by EGF-like factors. For instance, explants of preovulatory mice follicles treated with $\mathrm{LH}$ and AG14780 (EGFR kinase inhibitor) showed no expression of Ptgs2 (Ashkenazi et al. 2005). Similarly, reduced PTGS2 was noted when bovine GCs that were treated with the FRS, an adenylyl cyclase activator and an inhibitor of EGFR tyrosine kinase activity (Sayasith et al. 2013). In a recent study, EGFR knockdown has resulted in reduced expression of PTGS2 and decreased PGE2 (Fang et al. 2013).

We found that PTGS2 knockdown resulted in decreased expression of AREG and EREG. Also, exogenous PGE2 upregulate the expression of both AREG and EREG. Expression of TNFAIP6 was similarly reduced in PTGS2-silenced GCs and induction of TNFAIP6 by exogenous PGE2. Our data therefore support the notion that $A R E G$ and EREG are regulated by PTGS2 as observed in Ptgs2-knockout mice. Our data also point out that TNFAIP6 is yet another downstream target of PTGS2. Considering the major effect induced by LH/cAMP on these genes, shown here and in many other studies, a likely scenario of post-LH events would suggest that PGs provide a secondary, autocrine pathway to regulate the expression of EGF-like peptide in GCs. However, it is also plausible that AREG and EREG can in turn provide an additional signal to further induce PTGS2 and PGs. These multiple-positive autocrine loops would ensure a successful ovulatory process.

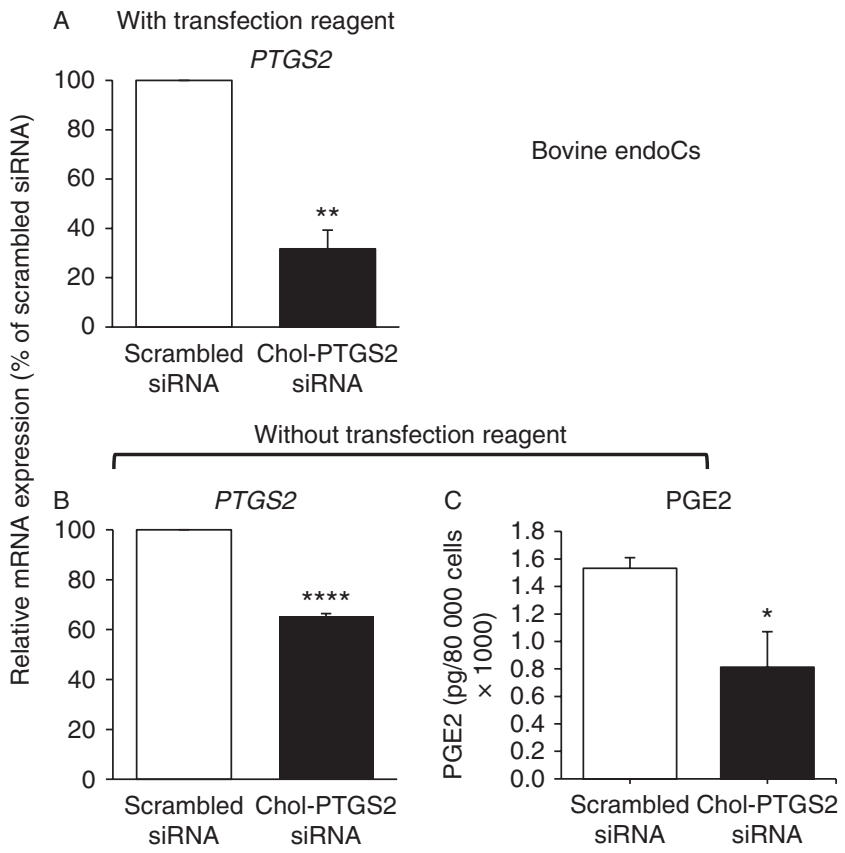

Figure 6 Cholesterol-conjugated PTGS2 siRNA treatment in bovine endometrial cells (bovine EndoCs) with and without transfection reagent. Endometrial cells were transfected or treated with $50 \mathrm{nmol} / \mathrm{l}$ of scrambled siRNA; designated $100 \%$ or cholesterol-conjugated PTGS2 siRNA (chol-PTGS2 siRNA). $24 \mathrm{~h}$ post transfection/treatment PMA $(100 \mathrm{~g} / \mathrm{ml})$ was added and RNA was extracted $48 \mathrm{~h}$ post transfection/ treatment for determination of PTGS2 mRNA using quantitative real-time PCR. (A) PTGS2 expression in transfected cells. PTGS2 expression (B) and PGE2 concentrations in culture media (C) of siRNA treated non-transfected cells. The data were obtained from three independent experiments. ${ }^{*} P<0.05,{ }^{* *} P<0.01$ and ${ }^{* * * *} P<0.0001$ indicate significant differences from scrambled siRNA. 


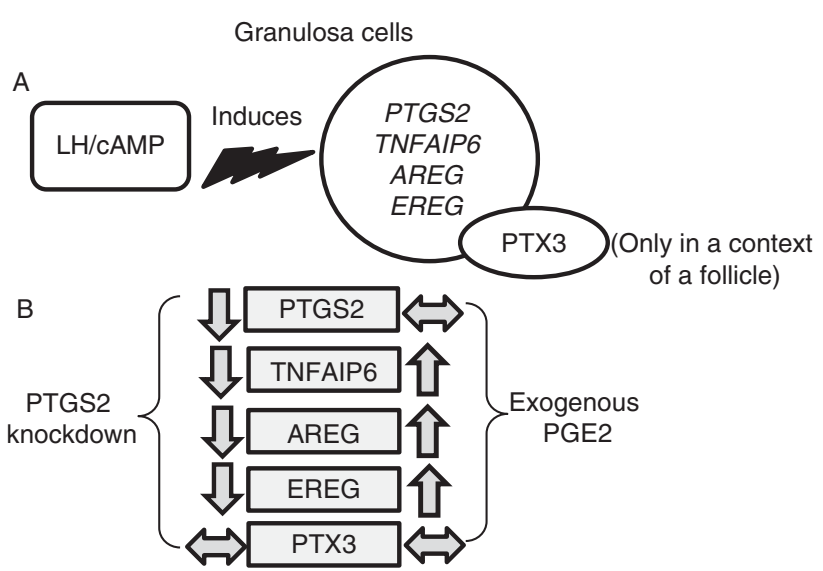

Figure 7 Schematic summary demonstrating induction of ovulatory genes by LH/CAMP and PGE2 in bovine GCs. (A) Role of LH/CAMP on the induction of ovulatory genes. GCs collected from cows $21 \mathrm{~h}$ after GNRH-induced LH surge upregulated the expression of following ovulatory genes: PTGS2, TNFAIP6, AREG, EREG and PTX3. Except $P T X 3$, the other genes were also induced in vitro by forskolin, directly activating adenynyl cyclase in isolated GCs culture. (B) Role of PGE2 on the expression of ovulatory gene. The mRNA levels of PTGS2 were significantly inhibited by $70 \%$ compared with cells treated with scrambled siRNA. Concentrations of PGE2 in the cell culture media were also markedly reduced to $<1 / 3$ as compared with control. Along with the silencing of PTGS2, the expression of TNFAIP6, AREG and EREG was significantly downregulated. PTX3 was not affected by PTGS2 silencing. In agreement with PTGS2 silencing, incubation with PGE2 $(1 \mu \mathrm{M})$ for $6 \mathrm{~h}$ elevated the mRNA levels of TNFAIP6, AREG and EREG, but not PTX3.

Previous studies employed PTGS2 inhibitors to examine the role of PTGS2 and PGE2 on ovulatory genes. The inhibitors used such as INDO are nonspecific as they also affect PTGS1, but even PTGS2 inhibitors can have non-specific effects if not calibrated precisely. In this study, we employed siRNA silencing of PTGS2 instead, which provides a specific and effective tool to critically examine the role of PGs in GCs in vitro but may also allow manipulation of ovulatory process. Furthermore, by inhibiting the mRNA rather than the protein, a more profound and longer inhibition can be achieved. Introducing the inhibitory sequence into small hairpin RNA (shRNA) plasmid can be used for stable knockdown. Furthermore, siRNA provides a means for a post-transcriptional gene regulation in vitro, but also in vivo in species where gene knockout is not feasible. Under in vivo conditions transfection reagents may exhibit immunostimulatory effects and toxicity (Dass 2004). Conjugation of cholesterol, a lipophilic molecule, with siRNA can facilitate the entry of siRNA without the need of transfection reagent (Yuan et al. 2008, Medvedeva et al. 2009, Wu et al. 2009). CholPTGS2 siRNA can be therefore used in various cell types expressing PTGS2. In the reproductive tract, EndoCs are most relevant where PTGS2-derived PGs plays a central role in the regulation of the estrous cycle, pregnancy recognition, pregnancy maintenance and parturition (Charpigny, Reinaud et al. 1997, Asselin, Lacroix et al. 1997, Fuchs, Rust et al. 1999, Liu, Antaya et al. 2001). In this study, we found chol-PTGS2 siRNA without transfection reagent to be effective in EndoCs, suggesting that this molecule can be administered locally in the uterine horn of farm animals to decisively examine the role of PTGS2 during the estrous cycle or pregnancy. In contrast, chol-PTGS2 siRNA was not effective in GCs without transfection reagent, the possible reasons are not clear, but it might be related with differences in membrane composition and/or the fact that EndoCs are proliferating at higher rates as compared with GCs.

In conclusion, our data confirm that the induction of ovulatory genes in bovine GCs, such as PTGS2, AREG, EREG and TNFAIP6, is dependent on LH/CAMP in vivo and in vitro. We had achieved a successful and specific knockdown of PTGS2 in GCs. PTGS2 silencing also caused significant reduction in mRNA levels of $A R E G$, EREG and TNFAIP6. Exogenous PGE2 increased these genes, further confirming that these genes are prostanoid dependent. In isolated GCs culture, neither cAMP nor PGE2 elevated PTX3. PTGS2 knockdown in GCs and EndoCs can be utilised to critically determine the functions of PTGS2 in vitro. siRNA ablation of PTGS2 in the reproductive tract as well as of other genes through local delivery may provide a novel approach for studying gene functions in large animals in vivo.

\section{Declaration of interest}

The authors declare that there is no conflict of interest that could be perceived as prejudicing the impartiality of the research reported.

\section{Funding}

Supported by a grant from Chief Scientist of the Israeli Ministry of Agriculture (R Meidan and U Moallem).

\section{Acknowledgements}

The authors thank Dr A F Parlow and National Hormone and Peptide program for providing human chorionic gonadotropin.

\section{References}

Arosh JA, Parent J, Chapdelaine P, Sirois J \& Fortier MA 2002 Expression of cyclooxygenases 1 and 2 and prostaglandin $E$ synthase in bovine endometrial tissue during the estrous cycle. Biology of Reproduction 67 161-169. (doi:10.1095/biolreprod67.1.161)

Ashkenazi H, Cao X, Motola S, Popliker M, Conti M \& Tsafriri A 2005 Epidermal growth factor family members: endogenous mediators of the ovulatory response. Endocrinology 146 77-84. (doi:10.1210/en.2004-0588)

Asselin E, Lacroix D \& Fortier MA 1997 IFN-tau increases PGE2 production and COX-2 gene expression in the bovine endometrium in vitro. Molecular and Cellular Endocrinology 132 117-126. 
Bahr A \& Wolf E 2012 Domestic animal models for biomedical research. Reproduction in Domestic Animals 47 59-71. (doi:10.1111/j.14390531.2012.02056.x)

Ben-Ami I, Freimann S, Armon L, Dantes A, Strassburger D, Friedler S, Raziel A, Seger R, Ron-El R \& Amsterdam A 2006 PGE2 up-regulates EGF-like growth factor biosynthesis in human granulosa cells: new insights into the coordination between PGE2 and LH in ovulation. Molecular Human Reproduction 12 593-599. (doi:10.1093/molehr/ gal068)

Breen SM, Andric N, Ping T, Xie F, Offermans S, Gossen JA \& Ascoli M 2013 Ovulation involves the luteinizing hormone-dependent activation of $\mathrm{G}(\mathrm{q} / 11)$ in granulosa cells. Molecular Endocrinology 27 1483-1491. (doi:10.1210/me.2013-1130)

Bridges PJ \& Fortune JE 2007 Regulation, action and transport of prostaglandins during the periovulatory period in cattle. Molecular and Cellular Endocrinology 263 1-9. (doi:10.1016/j.mce.2006.08.002)

Charpigny G, Reinaud P, Tamby JP, Creminon C, Martal J, Maclouf J \& Guillomot M 1997 Expression of cyclooxygenase-1 and -2 in ovine endometrium during the estrous cycle and early pregnancy. Endocrinology 138 2163-2171.

Cherny RA \& Findlay JK 1990 Separation and culture of ovine endometrial epithelial and stromal cells: evidence of morphological and functional polarity. Biology of Reproduction 43 241-250. (doi:10.1095/biolreprod43.2.241)

Christenson LK, Gunewardena S, Hong X, Spitschak M, Baufeld A \& Vanselow J 2013 Research resource: preovulatory LH surge effects on follicular theca and granulosa transcriptomes. Molecular Endocrinology 27 1153-1171. (doi:10.1210/me.2013-1093)

Conti M, Hsieh M, Park JY \& Su YQ 2006 Role of the epidermal growth factor network in ovarian follicles. Molecular Endocrinology $\mathbf{2 0}$ 715-723. (doi:10.1210/me.2005-0185)

Dass CR 2004 Lipoplex-mediated delivery of nucleic acids: factors affecting in vivo transfection. Journal of Molecular Medicine 82 579-591. (doi:10. 1007/s00109-004-0558-8)

Davis BJ, Lennard DE, Lee CA, Tiano HF, Morham SG, Wetsel WC \& Langenbach R 1999 Anovulation in cyclooxygenase-2-deficient mice is restored by prostaglandin E2 and interleukin-1 $\beta$. Endocrinology $\mathbf{1 4 0}$ 2685-2695.

Dinchuk JE, Car BD, Focht RJ, Johnston JJ, Jaffee BD, Covington MB, Contel NR, Eng VM, Collins RJ, Czerniak PM et al. 1995 Renal abnormalities and an altered inflammatory response in mice lacking cyclooxygenase II. Nature 378 406-409. (doi:10.1038/378406a0)

Fan HY, Liu Z, Johnson PF \& Richards JS 2011 CCAAT/enhancer-binding proteins (C/EBP) $-\alpha$ and $-\beta$ are essential for ovulation, luteinization, and the expression of key target genes. Molecular Endocrinology 25 253-268. (doi:10.1210/me.2010-0318)

Fang L, Cheng JC, Chang HM, Sun YP \& Leung PC 2013 EGF-like growth factors induce COX-2-derived PGE2 production through ERK1/2 in human granulosa cells. Journal of Clinical Endocrinology and Metabolism 98 4932-4941. (doi:10.1210/jc.2013-2662)

Fuchs AR, Rust W \& Fields MJ 1999 Accumulation of cyclooxygenase-2 gene transcripts in uterine tissues of pregnant and parturient cows: stimulation by oxytocin. Biology of Reproduction $60341-348$.

Fulop C, Szanto S, Mukhopadhyay D, Bardos T, Kamath RV, Rugg MS, Day AJ, Salustri A, Hascall VC, Glant TT et al. 2003 Impaired cumulus mucification and female sterility in tumor necrosis factor-induced protein-6 deficient mice. Development 130 2253-2261. (doi:10.1242/ dev.00422)

levoli E, Lindstedt R, Inforzato A, Camaioni A, Palone F, Day AJ, Mantovani A, Salvatori G \& Salustri A 2011 Implication of the oligomeric state of the N-terminal PTX3 domain in cumulus matrix assembly. Matrix Biology 30 330-337. (doi:10.1016/j.matbio.2011. 05.002)

Klipper E, Tatz E, Kisliouk T, Vlodavsky I, Moallem U, Schams D, Lavon Y, Wolfenson D \& Meidan R 2009 Induction of heparanase in bovine granulosa cells by luteinizing hormone: possible role during the ovulatory process. Endocrinology 150 413-421. (doi:10.1210/en.20080697)

Lee TH, Wisniewski HG \& Vilcek J 1992 A novel secretory tumor necrosis factor-inducible protein (TSG-6) is a member of the family of hyaluronate binding proteins, closely related to the adhesion receptor CD44. Journal of Cell Biology 116 545-557. (doi:10.1083/jcb.116.2.545)
Li Q, Jimenez-Krassel F, Ireland JJ \& Smith GW 2009 Gene expression profiling of bovine preovulatory follicles: gonadotropin surge and prostanoid-dependent up-regulation of genes potentially linked to the ovulatory process. Reproduction 137 297-307. (doi:10.1530/REP08-0308)

Liu J, Carriere PD, Dore M \& Sirois J 1997 Prostaglandin G/H synthase-2 is expressed in bovine preovulatory follicles after the endogenous surge of luteinizing hormone. Biology of Reproduction 57 1524-1531. (doi:10. 1095/biolreprod57.6.1524)

Liu J, Antaya M, Goff AK, Boerboom D, Silversides DW, Lussier JG \& Sirois J 2001 Molecular characterization of bovine prostaglandin $\mathrm{G} / \mathrm{H}$ synthase-2 and regulation in uterine stromal cells. Biology of Reproduction 64 983-991.

Medvedeva DA, Maslov MA, Serikov RN, Morozova NG, Serebrenikova GA, Sheglov DV, Latyshev AV, Vlassov VV \& Zenkova MA 2009 Novel cholesterol-based cationic lipids for gene delivery. Journal of Medicinal Chemistry 52 6558-6568. (doi:10.1021/ jm901022t)

Meidan R, Girsh E, Blum O \& Aberdam E 1990 In vitro differentiation of bovine theca and granulosa cells into small and large luteal-like cells: morphological and functional characteristics. Biology of Reproduction 43 913-921. (doi:10.1095/biolreprod43.6.913)

Mukhopadhyay D, Hascall VC, Day AJ, Salustri A \& Fulop C 2001 Two distinct populations of tumor necrosis factor-stimulated gene- 6 protein in the extracellular matrix of expanded mouse cumulus cell-oocyte complexes. Archives of Biochemistry and Biophysics 394 173-181. (doi:10.1006/abbi.2001.2552)

Ochsner SA, Day AJ, Rugg MS, Breyer RM, Gomer RH \& Richards JS 2003 Disrupted function of tumor necrosis factor- $\alpha$-stimulated gene 6 blocks cumulus cell-oocyte complex expansion. Endocrinology 144 4376-4384. (doi:10.1210/en.2003-0487)

Parent J \& Fortier MA 2005 Expression and contribution of three different isoforms of prostaglandin $E$ synthase in the bovine endometrium. Biology of Reproduction 73 36-44. (doi:10.1095/biolreprod. 104.037036)

Park JY, Su YQ, Ariga M, Law E, Jin SL \& Conti M 2004 EGF-like growth factors as mediators of LH action in the ovulatory follicle. Science 303 682-684. (doi:10.1126/science.1092463)

Peters MW, Pursley JR \& Smith GW 2004 Inhibition of intrafollicular PGE2 synthesis and ovulation following ultrasound-mediated intrafollicular injection of the selective cyclooxygenase-2 inhibitor NS-398 in cattle. Journal of Animal Science 82 1656-1662.

Richards JS 1994 Hormonal control of gene expression in the ovary. Endocrine Reviews 15 725-751. (doi:10.1210/edrv-15-6-725)

Richards JS 2001 Perspective: the ovarian follicle - a perspective in 2001. Endocrinology 142 2184-2193.

Richards JS 2005 Ovulation: new factors that prepare the oocyte for fertilization. Molecular and Cellular Endocrinology 234 75-79. (doi:10.1016/j.mce.2005.01.004)

Salustri A, Camaioni A \& D'Alessandris C 1996 Endocrine and paracrine regulation of cumulus expansion. Zygote 4 313-315. (doi:10.1017/ S0967199400003312)

Salustri A, Garlanda C, Hirsch E, De Acetis M, Maccagno A, Bottazzi B, Doni A, Bastone A, Mantovani G, Beck Peccoz P et al. 2004 PTX3 plays a key role in the organization of the cumulus oophorus extracellular matrix and in in vivo fertilization. Development 131 1577-1586. (doi:10.1242/ dev.01056)

Sayasith K, Lussier J, Dore M \& Sirois J 2013 Human chorionic gonadotropin-dependent up-regulation of epiregulin and amphiregulin in equine and bovine follicles during the ovulatory process. General and Comparative Endocrinology 180 39-47. (doi:10.1016/j.ygcen.2012. 10.012)

Shimada M, Hernandez-Gonzalez I, Gonzalez-Robayna I \& Richards JS 2006 Paracrine and autocrine regulation of epidermal growth factorlike factors in cumulus oocyte complexes and granulosa cells: key roles for prostaglandin synthase 2 and progesterone receptor. Molecular Endocrinology 20 1352-1365. (doi:10.1210/me.20050504)

Sirois J 1994 Induction of prostaglandin endoperoxide synthase-2 by human chorionic gonadotropin in bovine preovulatory follicles in vivo. Endocrinology 135 841-848. 
Sirois J \& Richards JS 1992 Purification and characterization of a novel, distinct isoform of prostaglandin endoperoxide synthase induced by human chorionic gonadotropin in granulosa cells of rat preovulatory follicles. Journal of Biological Chemistry 267 6382-6388.

Tsai SJ, Wiltbank MC \& Bodensteiner KJ 1996 Distinct mechanisms regulate induction of messenger ribonucleic acid for prostaglandin (PG) G/H synthase-2, PGE (EP3) receptor, and PGF2 $\alpha$ receptor in bovine preovulatory follicles. Endocrinology 137 3348-3355.

Vanselow J, Spitschak M, Nimz M \& Furbass R 2010 DNA methylation is not involved in preovulatory down-regulation of CYP11A1, HSD3B1, and CYP19A1 in bovine follicles but may have a role in permanent silencing of CYP19A1 in large granulosa lutein cells. Biology of Reproduction 82 289-298. (doi:10.1095/biolreprod.109. 079251)

Varani S, Elvin JA, Yan C, DeMayo J, DeMayo FJ, Horton HF, Byrne MC \& Matzuk MM 2002 Knockout of pentraxin 3, a downstream target of growth differentiation factor-9, causes female subfertility. Molecular Endocrinology 16 1154-1167. (doi:10.1210/mend.16.6.0859)
Wu Y, Navarro F, Lal A, Basar E, Pandey RK, Manoharan M, Feng Y, Lee SJ, Lieberman J \& Palliser D 2009 Durable protection from Herpes simplex virus-2 transmission following intravaginal application of siRNAs targeting both a viral and host gene. Cell Host \& Microbe 5 84-94. (doi:10.1016/j.chom.2008.12.003)

Yuan H, Lanting L, Xu ZG, Li SL, Swiderski P, Putta S, Jonnalagadda M, Kato M \& Natarajan R 2008 Effects of cholesterol-tagged small interfering RNAs targeting 12/15-lipoxygenase on parameters of diabetic nephropathy in a mouse model of type 1 diabetes. American Journal of Physiology. Renal Physiology 295 605-617. (doi:10.1152/ajprenal. 90268.2008)

Received 3 July 2014

First decision 30 August 2014

Revised manuscript received 9 September 2014

Accepted 16 October 2014 